\title{
Horse Riding Simulator Affect the Posture Alignment of Young Adults with Forward Head Posture
}

\author{
Chu-Yi Hong $\cdot$ Nam-Jin Jung $\cdot$ Sang-Su Na $\cdot$ Gak Hwangbo ${ }^{1 \dagger}$ \\ Department of Rehabilitation Sciences, Graduate School, Daegu University \\ ${ }^{1}$ Department of Physical Therapy, College of Rehabilitation Sciences, Daegu University
}

Received: September 13, 2016 / Revised: September 19, 2016 / Accepted: October 7, 2016

(C) 2016 J Korean Soc Phys Med

\section{| Abstract |}

PURPOSE: The purpose of this study was to compare the effect of correction on posture parameters between a horse riding simulator exercise and a conventional exercise occurring in an open linear chain linking the head to the pelvis in the sagittal plane of young adults with a forward head posture.

METHODS: In this study, 30 subjects were randomly divided into two groups of 15 subjects each, were assigned to the horse riding simulator exercise or the neck exercise group and they performed exercise 30 minutes per each round two times a week for six weeks. To determine the subjects' forward head posture, the three angles and three distances were measured.

RESULTS: The forward head angle and head distance results showed a significant change between pre and post intervention in both group. The horizontal distance between acromion and tragus results showed a significant change between pre and post intervention in neck exercise group

†Corresponding Author : hbgak@daegu.ac.kr

This is an Open Access article distributed under the terms of the Creative Commons Attribution Non-Commercial License (http://creativecommons.org/licenses/by-nc/3.0) which permits unrestricted non-commercial use, distribution, and reproduction in any medium, provided the original work is properly cited.
(CG), but no significant change in horse riding simulator exercise group (EG). The averages of each measured values of EG and CG before and after were compared, but there are no significant different between groups.

CONCLUSION: Although the effects of the horse riding exercise were lower than those elicited by the neck exercise, the results demonstrated that the horse riding simulator exercise improved posture alignment for subjects with forward head posture. Therefore, the horse riding simulator exercise can constitute an appropriate alternative exercise for subjects with forward head posture.

Key Words: Horse riding simulator exercise, Forward head position, Posture alignment

\section{Introduction}

In modern society, the development of the economy and technology might lead to modern diseases, such as neck pain, because of an increase in the number of health issues and a lack of exercise (Kim and Kim, 2014; Lee et al., 2011). Someone who often has to sit at work for prolonged periods or who usually has an improper head position during work may have a serious risk of neck pain occurrence (Nejati et al., 2015). Persistent neck pain is often considered associated with abnormalities in head 
posture (Borestein et al., 2004). A smaller craniovertebral angle was correlated with neck pain severity and disability (Yip et al., 2008; Silva et al., 2009). There is a consensus that a forward head posture (FHP) is the excessive anterior positioning of the head in relation to a vertical reference line in a sitting or standing posture (Harman et al., 2005; Lee et al., 2015). According to the literature, a FHP is associated with a weakening of the deep cervical short flexor muscles and mid-thoracic scapular retractors (i.e., rhomboids, serratus anterior, and middle and lower trapezius) and a shortening of the opposing cervical extensors and pectoralis muscles (Kendall et al., 1993; Darling et al., 1984; Lee et al., 2015). Moreover, abnormal posture patterns could be associated with short anterior or posterior muscles that might influence trunk kinematics and muscle activity differently in standing and sitting positions (Al-Eisa et al., 2006).

Hippotherapy and therapeutic horseback riding as a promising alternative rehabilitation technique have gained the certification of improving postural stability, improving locomotor performance among adults and children with neurological impairments (Park et al., 2014; SilkwoodSherer and Warmbier, 2007). Horseback riding therapy is a form of treatment that provides movements of the pelvis and hip, trunk, and head, as well as balance in response to the horse's movements (Borges et al., 2011). In general, the effect of horseback riding exercise has been proven through previous studies, as follows: muscular endurance, agility, coordination, flexibility, balance, aerobic and anaerobic capacity. A recent study aimed to prove an indoor horse riding simulator exercise enhances muscle strength in the trunk and abdominal parts (Yu et al., 2014), but few studies directly assessed the impact of a targeted horse riding simulator exercise on FHP (Kim et al., 2015).

Accordingly, the purpose of this study was to compare the effect of correction on posture parameters between a horse riding simulator exercise and a conventional exercise occurring in an open linear chain linking the head to the pelvis in the sagittal plane of young adults with a FHP. This study went further to identify the effectiveness of a horse riding simulator exercise to improve FHP.

\section{Methods}

\section{Experimental Procedures}

In this study 30 subjects, attending D University in Gyeongsan, South Korea whose craniovertebral angle (CVA) was less than 52 degrees and who had no horse riding exercise experience and no medical history or drug treatment, participated in this study. Subjects were excluded if they met any of the following conditions: had experienced cervical fracture or trauma, bone cancer, neurological motion disorders, restrictions in lung function, or other neurologic, orthopedic; or had undergone thoracic or abdominal surgery. Informed consent was voluntarily obtained from all the subjects prior to participation in the study.

Table 1. General Characteristics of subjects

\begin{tabular}{ccccc}
\hline & EG $(\mathrm{n}=15)$ & CG $(\mathrm{n}=15)$ & $\mathrm{t}$ & $\mathrm{P}$ \\
\hline Age (year) & $22.67 \pm 3.37$ & $21.73 \pm 1.48$ & -.981 & .335 \\
\hline Sex (male/female) & $7 / 8$ & $4 / 11$ & 1.122 & .271 \\
\hline Height $(\mathrm{cm})$ & $168.73 \pm 6.07$ & $164.27 \pm 7.96$ & -1.726 & .095 \\
\hline Mass $(\mathrm{kg})$ & $70.20 \pm 12.90$ & $64.33 \pm 13.46$ & -1.218 & .233 \\
\hline BMI $(\mathrm{kg} / \mathrm{m})$ & $24.66 \pm 4.52$ & $23.73 \pm 4.10$ & -.591 & .599 \\
\hline
\end{tabular}

EG: Horse riding simulator exercise group

CG: Neck exercise group 
Subjects were randomly divided into two groups of 15 subjects each, were assigned to the horse riding simulator exercise or the neck exercise group and they performed exercise 30 minutes per each round two times a week for six weeks. Table 1 was the general characteristics of subjects.

\section{1) Horse riding simulator program}

A horse riding simulator was used for the experiment in this study. It is created movements similar to a horse, and an indoor HRS H-702 (Honjin, Korea). Subjects had 5 minutes to prepare. After the start of horse riding exercise, the participants based their abilities to adjust speed.

\section{2) Neck exercise program}

The neck exercise group received a corrective exercise program for forward head posture in the form of two strengthening (deep cervical flexors and shoulder retractors) and two stretching (cervical extensor and pectoral muscles) Participants completed three sets of 12 repetitions of the strengthening exercise and three stretching exercises held for 30 seconds (Harman et al., 2005; Diab, 2012).

\section{Measurement}

Age, height, and body mass were recorded. To best display anatomical landmarks and their posture, participants were measured by wearing tight shorts and sleeveless T-shirts.

All measurement procedure was followed by previous study (Harman et al., 2005). Forward head position is often measured as three angles and three distances (Fig. 1, 2).

\section{Sagittal posture measurement}

To determine the subjects' posture, the three angles and three distances commonly used to assess forward head posture, that were calculated by using Adobe Photoshop CS6. To minimize image distortion, the assessor placed a circular spirit level at the base of the camera to ensure that the camera was positioned perpendicular to the horizontal. Six adhesive markers were placed over anatomical landmarks. The markers were made in $\mathrm{C}$, tragus, acromion, glabella, anterior superior iliac spine

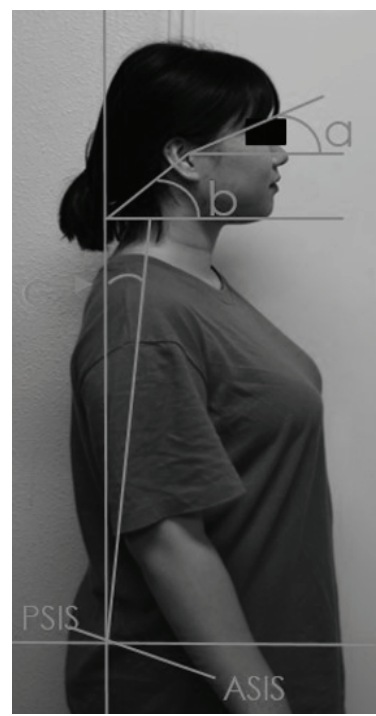

Fig. 1. Description of postural angles measurement from the photographs

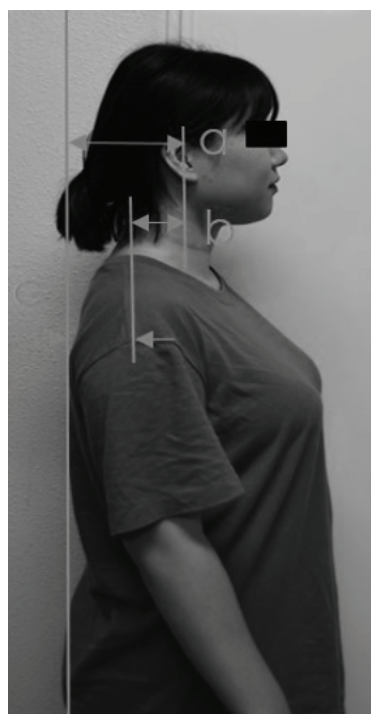

Fig. 2. Description of postural distances measurement from the photographs 
(ASIS) and posterior superior iliac spine (PSIS). A tripod-mounted digital camera was set 33 inches from the ground and 104 inches from a wall-mounted grid, and participants stood inches from the wall. There repeated pictures in standing were taken about right sagittal views pre- and post-intervention. A second set of photographs was taken using the same protocol after the 6-week exercise by the same physiotherapist.

Three angles were measured; 1) Head angle is the angle between horizontal and the glabella-to-tragus line. 2) Forward head angle is the angle between horizontal and the tragus-to-C7 line. 3) Shoulder-to-pelvis angle (SPA) is the angle is between vertical and the line joining acromion to mid-point between ASIS and PSIS.

Three distances were measured: 1) Head distance is the horizontal distance from tragus to vertical plumb frombase of fifth metatarsal. 2) HScal is the horizontal distance between acromion and tragus. 3) Shoulder distance is the horizontal distance from acromion to vertical plumb from base of fifth metatarsal.

\section{Statistical analysis}

This study used SPSS for Windows (version 18.0) to analyze the data. The independent $\mathrm{t}$-test was used to determine if there are any different between the groups in age, body mass, and height.

In postural analysis, the paired t-test was used to compare the changes of 3 angles and 3 distances between before and after the intervention, and the independent t-test was used to compare the results between the two groups. The statistical significance level was set at $\mathrm{p}<.05$.

\section{Results}

\section{General subjects characteristics}

Thirty subjects participated in this study. Subjects were divided into the horse riding simulator exercise group (EG; $\mathrm{n}=15$ ) and neck exercise group (CG; $\mathrm{n}=15)$. The general characteristics of subjects who participated in the study are as in Table 1 . There are no statistically significant differences between the group for any of these measurements $(p>05)$.

Table 2. Mean of 3 angle and 3 distance of forward head posture in within group $(n=30)$

\begin{tabular}{ccccc}
\hline Variable & Group & Pre-intervention & Post-intervention & $\begin{array}{c}\text { Within group } \\
\text { (p-value })\end{array}$ \\
\hline \multirow{2}{*}{ Head angle $\left(^{\circ}\right)$} & EG & $23.64 \pm 4.95^{\mathrm{a}}$ & $23.64 \pm 5.99$ & .999 \\
& CG & $21.08 \pm 6.19$ & $22.98 \pm 6.06$ & .061 \\
\hline \multirow{2}{*}{ Forward head angle $\left(^{\circ}\right)$} & EG & $49.93 \pm 3.20$ & $55.31 \pm 3.64$ & $.000^{* *}$ \\
& CG & $50.00 \pm 2.54$ & $56.22 \pm 3.66$ & $.000^{* *}$ \\
\hline \multirow{2}{*}{ Shoulder to Pelvis angle $\left(^{\circ}\right)$} & EG & $-1.66 \pm 3.48$ & $-1.66 \pm 4.02$ & 1.000 \\
& CG & $-2.63 \pm 3.79$ & $-2.59 \pm 2.16$ & .967 \\
\hline \multirow{2}{*}{ Head distance $(\mathrm{cm})$} & EG & $4.33 \pm 2.59$ & $1.00 \pm 3.08$ & $.004^{* *}$ \\
& CG & $2.54 \pm 3.19$ & $-.03 \pm 3.20$ & $.010^{*}$ \\
\hline \multirow{2}{*}{ HScal $(\mathrm{cm})$} & EG & $5.16 \pm 2.77$ & $3.39 \pm 2.59$ & .074 \\
& CG & $5.21 \pm 2.27$ & $3.34 \pm 1.50$ & $.003^{* *}$ \\
\hline \multirow{2}{*}{ Shoulder distance $(\mathrm{cm})$} & EG & $-.83 \pm 3.04$ & $-2.39 \pm 3.48$ & .205 \\
& CG & $-2.66 \pm 3.89$ & $-3.37 \pm 2.76$ & .520 \\
\hline
\end{tabular}

${ }^{*} \mathrm{p}<.05, * * \mathrm{p}<.01$

EG: Horse riding simulator exercise group.

CG: Neck exercise group. 
Table 3. Mean of 3 angle and 3 distance of forward head posture in between group $(n=30)$

\begin{tabular}{|c|c|c|c|c|}
\hline Variable & Stage & EG & CG & $\begin{array}{c}\text { Between group } \\
(p-v a l u e)\end{array}$ \\
\hline \multirow{2}{*}{ Head angle $\left({ }^{\circ}\right)$} & Pre & $23.64 \pm 4.95$ & $21.08 \pm 6.19$ & .221 \\
\hline & Post & $23.64 \pm 5.99$ & $22.98 \pm 6.06$ & .766 \\
\hline \multirow{2}{*}{ Forward head angle $\left({ }^{\circ}\right)$} & Pre & $49.93 \pm 3.20$ & $50.00 \pm 2.54$ & .945 \\
\hline & Post & $55.31 \pm 3.64$ & $56.22 \pm 3.66$ & .499 \\
\hline \multirow{2}{*}{ Shoulder to Pelvis angle $\left({ }^{\circ}\right)$} & Pre & $-1.66 \pm 3.48$ & $-2.63 \pm 3.79$ & .474 \\
\hline & Post & $-1.66 \pm 4.02$ & $-2.59 \pm 2.16$ & .439 \\
\hline \multirow{2}{*}{ Head distance $(\mathrm{cm})$} & Pre & $4.33 \pm 2.59$ & $2.54 \pm 3.19$ & .105 \\
\hline & Post & $1.00 \pm 3.08$ & $-.03 \pm 3.20$ & .370 \\
\hline \multirow{2}{*}{ HScal $(\mathrm{cm})$} & Pre & $5.16 \pm 2.77$ & $5.21 \pm 2.27$ & .958 \\
\hline & Post & $3.39 \pm 2.59$ & $3.34 \pm 1.50$ & .940 \\
\hline \multirow{2}{*}{ Shoulder distance $(\mathrm{cm})$} & Pre & $-.83 \pm 3.04$ & $-2.66 \pm 3.89$ & .162 \\
\hline & Post & $-2.39 \pm 3.48$ & $-3.37 \pm 2.76$ & .398 \\
\hline
\end{tabular}

$* \mathrm{p}<.05,{ }^{*} \mathrm{p}<.01$

EG: Horse riding simulator exercise group.

CG: Neck exercise group.

\section{Comparison of posture alignment before and} after the intervention in 3 angle and 3 distance within groups.

The forward head angle and head distance results showed a significant change between pre and post intervention in both group. The Hscal results showed a significant change between pre and post intervention in CG, but no significant change in EG. There was no significant change in head angle, shoulder to pelvis angle and shoulder distance (Table 2).

\section{Comparison of posture alignment before and} after the intervention in 3 angle and 3 distance between groups.

The averages of each measured values of EG and CG before and after were compared, and the results are shown in Table 3. There are no significant different in groups.

\section{Discussion}

A forward head posture (FHP) is defined as poor posture of the cervical spine, and it has been related to neck pain, temporomandibular disorders, and cervicogenic and post-concussion headaches (Fernández-de-las-Peñas et al., 2007). To explore a better option to treat FHP, this study was conducted to compare the effects of a horse riding simulator exercise and a conventional neck exercise among young adults with FHP on postural alignment.

Regarding posture measurement, the two groups showed statistically significant differences in forward head angle and head distance between pre-test and post-test measurements. In addition, the neck exercise group showed significant differences in HScal (horizontal distance between acromion and tragus). However, there were no statistical differences between the two postural measurements in both groups (head angle and shoulder to pelvis angle). Furthermore, there were no statistical differences among all postural measurements between the two groups. 
Regarding the neck exercise, craniocervical flexor training involves performing and holding inner range positions of craniocervical flexion, the anatomical action of the deep cervical flexor muscles (Falla et al., 2007). This exercise has been shown to increase the activation of these muscles. The improved ability to maintain an upright position of the cervical spine, which was observed in the neck exercise group, may reflect an improved endurance of the deep cervical flexor muscles. It is a remarkable fact that the horse riding simulator exercise also influenced the postural parameters of the cervical spine. It appeared to improve the ability to maintain an upright posture of the cervical spine. A previous study suggested hippotherapy with a simulator could improve sitting balance in children with cerebral palsy who have higher levels of the disability (Herrero et al., 2012). Although subjects of these studies were children with different disabilities, these studies illustrated that a therapeutic horseback riding simulator exercise has the potential to improve postural control. In relation to this study, the foundations of the use of horse riding simulator therapy are reasonable, as it is directly related to improvements in postural alignment.

Head distance significantly decreased in both groups, but the horse riding simulator exercise group had a more significant decrease than the neck exercise group. The head distance is the horizontal distance from tragus to the vertical plumb from the base of the fifth metatarsal. From the kinematic point of view, the horse riding simulator exercise is not a targeted neck and shoulder exercise so much as a whole body exercise (Yu et al., 2014; Bertoti, 1988). Although the effects of the horse riding exercise were lower than those elicited by neck exercise were, it could still show its potential in terms of correcting FHP.

The HScal is the horizontal distance between the acromion and the tragus. The HScal decreased in both groups, but there was only a statistical decrease in the neck exercise group, as compared to the horse riding exercise group. A pervious study demonstrated persons with moderate FHP and rounded shoulder posture following an only two-week stretching program for the pectoralis muscle could improve resting scapular position (Roddey et al., 2002). Perhaps the explanation of the findings might lie in the fact that the stretching pectoral and shoulder muscle exercises in the horse riding simulator exercise group are not enough.

The use of horse riding simulators is controversial for some therapists, because it is said that it only imitates the mechanical pattern of movement and loses all the psychological aspects related to traditional horseback treatment. However, this therapy has a low cost when compared with real horses in terms of the animal maintenance, facility, and insurance costs. In addition, it is safer than live horses for the users, more accessible to people with restricted mobility, and its use does not depend on environmental conditions. It is also convenient to be used to treat indoors (Herrero et al., 2010). Finally, as compared to the neck exercise, the horse riding exercise has been gaining attention as a solution to overcoming boredom while exercising (Yu et al., 2014). Although previous studies have reported the beneficial role of horse simulator exercises in FHP (Kim et al., 2015), there are few studies about the effect of FHP on postural alignment around the spine or pelvis. Hence, this study undertook an investigation to reveal the effect of a horse simulator exercise for 6 weeks on the posture alignment of young adults with FHP.

This study has some limitations, one of which is the lack of accurate tools for the assessment of posture. Furthermore, this study did not investigate the statistical significance of muscle endurance and muscle activity in the posture-related muscles. Therefore, future studies should further expand on this study to evaluate muscle endurance and muscle activity in the posture-related muscles. 


\section{Conclusion}

In the posture measurement, there were statistically significant differences between the pre-test and post-test measurements for forward head angle, head distance, and HScal in the neck exercise group, while there were statistically significant differences in the measurements for forward head angle and head distance in the horse riding simulator exercise group. Although the effects of the horse riding exercise were lower than those elicited by the neck exercise, the results demonstrated that the horse riding simulator exercise improved posture alignment for subjects with FHP. Therefore, the horse riding simulator exercise can constitute an appropriate alternative exercise mode for subjects with FHP.

\section{References}

Al-Eisa E, Egan D, Deluzio K, et al. Effects of pelvic asymmetry and low back pain on trunk kinematics during sitting: a comparison with standing. Spine. 2006;31(5): E135-E43.

Bertoti DB. Effect of therapeutic horseback riding on posture in children with cerebral palsy. Phys Ther. 1988;68(10):1505-12.

Borenstein DG, Wiesel SW, Boden SD. Lowback and neck pain: Comprehensive diagnosis and management $\left(3^{\text {rd }}\right.$ ed). London. United kingdom. Elsvier Health Sciences. 2004.

Borges MBS, Werneck MJdS, Silva MdLd, et al. Therapeutic effects of a horse riding simulator in children with cerebral palsy. Arq Neuropsiquiatr. 2011;69(5): 799-804.

Darling D, Kraus S, Glasheen-Wray M. Relationship of head posture and the rest position of the mandible. J Prosthet Dent. 1984;52(1):111-5.

Diab AA. The role of forward head correction in management of adolescent idiopathic scoliotic patients: a randomized controlled trial. Clin Rehabil. 2012; 26(12):1123-32.

Dunleavy K, Neil J, Tallon A, et al. Reliability and validity of cervical position measurements in individuals with and without chronic neck pain. J Man Manip Ther. 2015;23(4):188-96.

Falla D, Jull G, Russell T, et al. Effect of neck exercise on sitting posture in patients with chronic neck pain. Phys Ther. 2007;87(4):408-17.

Fernándezde-las-Peñas C, Alonso-Blanco C, Cuadrado M, et al. Neck mobility and forward head posture are not related to headache parameters in chronic tensiontype headache. Cephalalgia. 2007;27(2):158-64.

Harman K, Hubley-Kozey CL, Butler H. Effectiveness of an exercise program to improve forward head posture in normal adults: a randomized, controlled 10-week trial. J Man Manip Ther. 2005;13(3):163-76.

Herrero P, Asensio Á, García E, et al. Study of the therapeutic effects of an advanced hippotherapy simulator in children with cerebral palsy: a randomised controlled trial. BMC Musculoskelet Disord. 2010;11(1):1

Herrero P, Gómez-Trullén EM, Asensio Á, et al. Study of the therapeutic effects of a hippotherapy simulator in children with cerebral palsy: a stratified single-blind randomized controlled trial. Clin Rehabil. 2012;26(12):1105-13.

Kendall FP, MoCreary EK, Provance PG, et al. Muscles, testing and function: with posture and pain. Philadelphia, United States. Lippincott Williams and Wikins. 1993.

Kim KH, Kim SG, Hwangbo G. The effects of horse-riding simulator exercise and Kendall exercise on the forward head posture. J Phys Ther Sci. 2015;27(4):1125-7.

Kim SH, Kim KU. Change of cervical angle according to smartphone using time. J Korean Soc Phys Med. 2014;9(2):141-9

Lee DR, Lee NG, Cha HJ, et al. The effect of robo-horseback riding therapy on spinal alignment and associated muscle 
size in MRI for a child with neuromuscular scoliosis: an experimenter-blind study. NeuroRehabilitation. 2011;29(1):23-7.

Lee HS, Lee WC, Kim JH. The effects of neck assistive device considering Mckenzie type subjects with forward head posture. J Korean Soc Phys Med. 2015;10(2):89-94.

Lee HS, Chung HK, Park SW. The Analysis of severity of forward head posture with observation and photographic method. J Korean Soc Phys Med. 2015;10(3):227-35.

Nejati P, Lotfian S, Moezy A, et al. The study of correlation between forward head posture and neck pain in Iranian office workers. Int J Occup Med Environ Health. 2015;28(2):295-303.

Park JH, Shurtleff T, Engsberg J, et al. Comparison between the robo-horse and real horse movements for hippotherapy. Biomed Mater Eng. 2014;24(6): 2603-10.

Roddey TS, Olson SL, Grant SE. The effect of pectoralis muscle stretching on the resting position of the scapula in persons with varying degrees of forward head/rounded shoulder posture. J Man Manip Ther. 2002;10(3):124-8.

Silkwood-Sherer D, Warmbier H. Effects of hippotherapy on postural stability, in persons with multiple sclerosis: a pilot study. J Neurol Phys Ther. 2007;31(2):77-84.

Silva AG, Punt TD, Sharples P, et al. Head posture and neck pain of chronic nontraumatic origin: a comparison between patients and pain-free persons. Arch Phys Med Rehabil. 2009;90(4):669-74.

Yip CHT, Chiu TTW, Poon ATK. The relationship between head posture and severity and disability of patients with neck pain. Man Ther. 2008;13(2):148-54.

Yu CH, Hong CU, Kang SR, et al. Analysis of basal physical fitness and lumbar muscle function according to indoor horse riding exercise. Biomed Mater Eng. 2014;24(6):2395-405. 